\title{
Adenocarcinoma arising from a gastric duplication cyst with invasion to the stomach: a case report with literature review
}

\author{
K Kuraoka, H Nakayama, T Kagawa, T Ichikawa, W Yasui
}

J Clin Pathol 2004;57:428-431. doi: 10.1136/jcp.2003.013946

This report describes a rare case of adenocarcinoma arising from a gastric duplication cyst, with invasion to the stomach wall, in a 40 year old Japanese man. A cystic lesion was found between the stomach and the spleen. The cyst had a well circumscribed smooth muscle layer, corresponding to the muscularis propria of the stomach and the mucosa of the alimentary tract. A well differentiated adenocarcinoma was found within the duplication cyst, invading its serosa. Well differentiated adenocarcinoma was independently found in the fundus of the stomach; the tumour of the cyst was connected by fibrous tissue. Microscopically, there was neither adenocarcinoma in situ nor precancerous lesions, such as epithelial dysplasia, suggesting that the carcinoma derived from a gastric duplication cyst that invaded the stomach. Duplication cysts should be included in the differential diagnosis of cystic masses of the gastrointestinal tract, and the possibility of malignancy within these cysts should be considered.

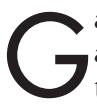
astrointestinal duplications are a relatively rare anomaly that may occur at any level, from the oral cavity to the rectum, with the ileum being the most common site. ${ }^{1}$ Duplications of the stomach are quite rare, and most have been reported in children. ${ }^{2}$ The essential criteria for making the diagnosis of a gastric duplication are summarised as follows: (a) the wall of the cyst is contiguous with the stomach wall; (b) the cyst is surrounded by smooth muscle, which is continuous with the muscle of the stomach; and (c) the cyst wall is lined by epithelium of gastric or any other type of gut mucosa. ${ }^{3}$ Carcinoma arising from a duplication cyst is extremely rare, with only five cases having been reported in gastric duplication cysts to date. ${ }^{4-8}$ We present a case of adenocarcinoma arising from a gastric duplication cyst with invasion to the stomach wall in a 40 year old Japanese man, together with a discussion of the literature.

"Carcinoma arising from a duplication cyst is extremely rare, with only five cases having been reported in gastric duplication cysts to date"

\section{CASE REPORT}

A 40 year old Japanese man was admitted to Hiroshima Municipal Funairi Hospital, Japan, with fever and back pain. A computed tomography scan (fig lA) and ultrasonography revealed a cystic lesion of $7 \mathrm{~cm}$ in diameter above the spleen. The cyst was thought to be a splenic cyst, with the slight possibility of malignancy, because the lumen of the cyst was nodular. A simple cystectomy was done. At surgery, the cyst was found to be located between the stomach and the spleen, which was covered by the greater omentum with fibrofibrinous peritonitis. The cyst was strongly adhered to the stomach and retroperitoneum and did not communicate with the gastric lumen. The patient's postoperative course was uneventful. One month after surgery, a protruding and ulcerative tumour was found at the gastric fundus, where the cyst had adhered, by endoscopic examination. Biopsy specimens from the tumour revealed a typical, well differentiated, tubular adenocarcinoma. A proximal gastrectomy was performed. Seven months after surgery, the patient had multiple liver metastases and received chemotherapy.

\section{METHODS}

The surgical specimens from the patient were fixed in $10 \%$ buffered formalin and processed for paraffin wax embedding. Multiple sections of different fragments were stained with haematoxylin and eosin. Serial sections were immunostained by the avidin-biotin-peroxidase complex technique with the primary antibodies listed in table 1. Antigen retrieval was carried out using high temperature incubation in citrate buffer (0.01 mol/litre, $\mathrm{pH} 6.0)$.

\section{Pathological findings}

The cystic lesion was $7 \mathrm{~cm}$ in diameter and was unilocular (fig 2A). The cyst contained dark serosanguinous fluid. The lumen was granular and the wall was elastic hard. Microscopically, the cyst wall had a well circumscribed smooth muscle layer, corresponding to the muscularis propria of the stomach (fig 2B). Although most of the epithelium lining the lumen was missing, simple cuboidal epithelium and ciliated pseudostratified epithelium were seen in part, which resembled mucosa of the alimentary tract in various embryonic stages (fig 2C, D). There were neither parietal nor chief cells. These findings were compatible with a

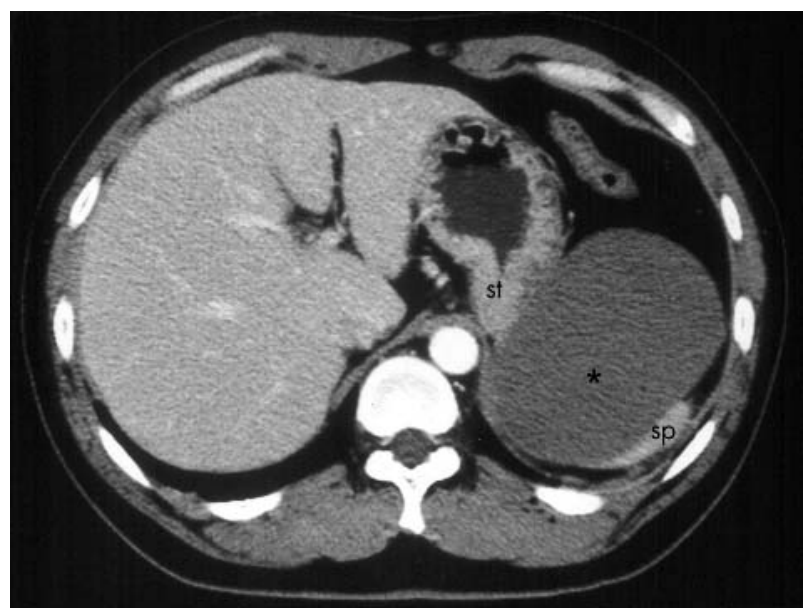

Figure 1 Computed tomography revealed a cystic lesion (asterisk) of $7 \mathrm{~cm}$ in diameter, located between the stomach (st) and the spleen (sp). 

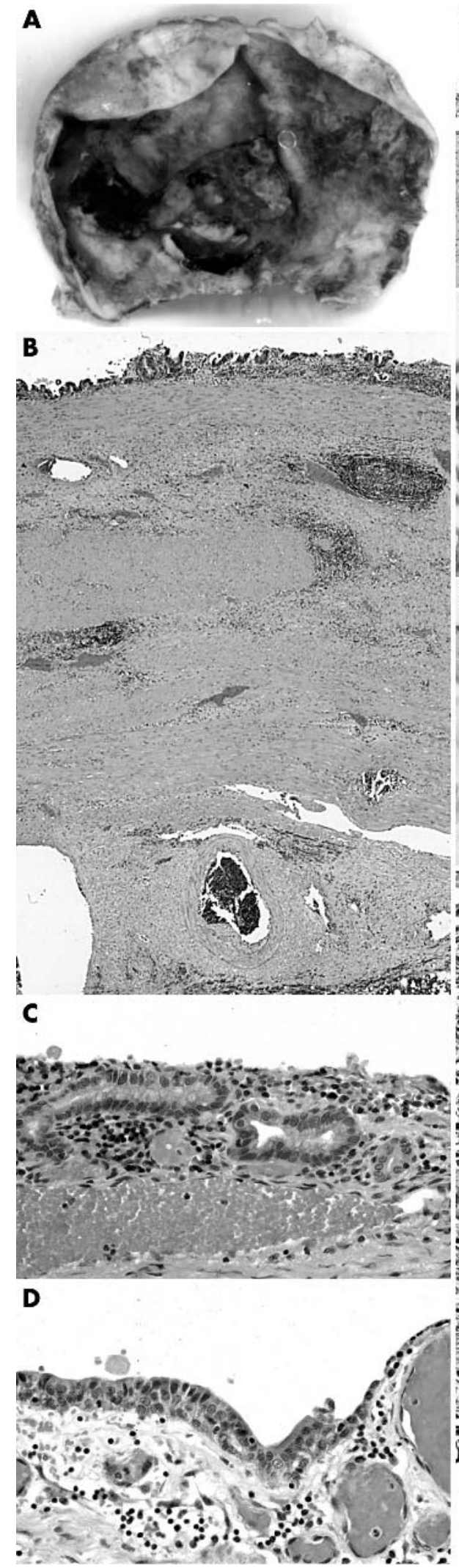

gastric duplication cyst. A well differentiated papillary or tubular adenocarcinoma was found within the duplication cyst (fig 2E, F). The tumour cells were immunopositive for human gastric mucin (HGM-45Ml) (fig $2 \mathrm{G}$ ). The carcinoma cells were immunonegative for cytokeratin 7 , whereas they
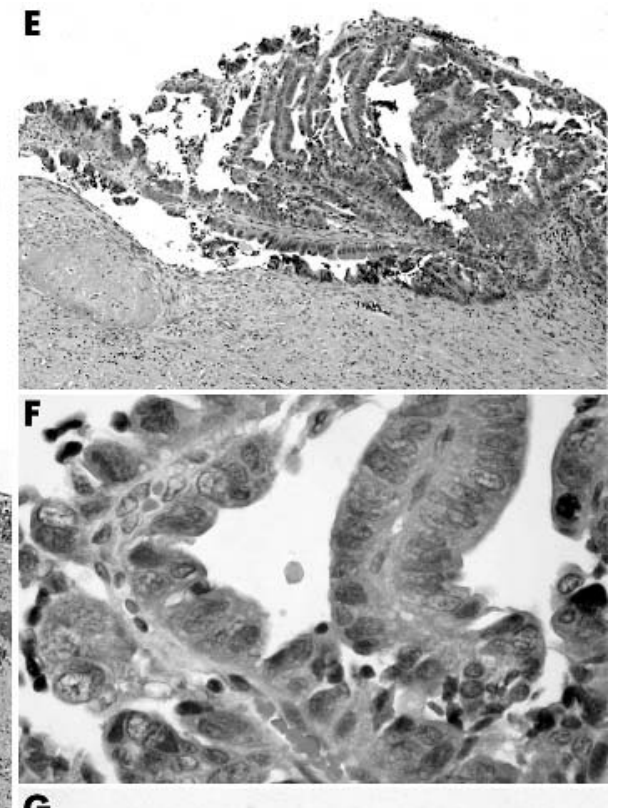

G
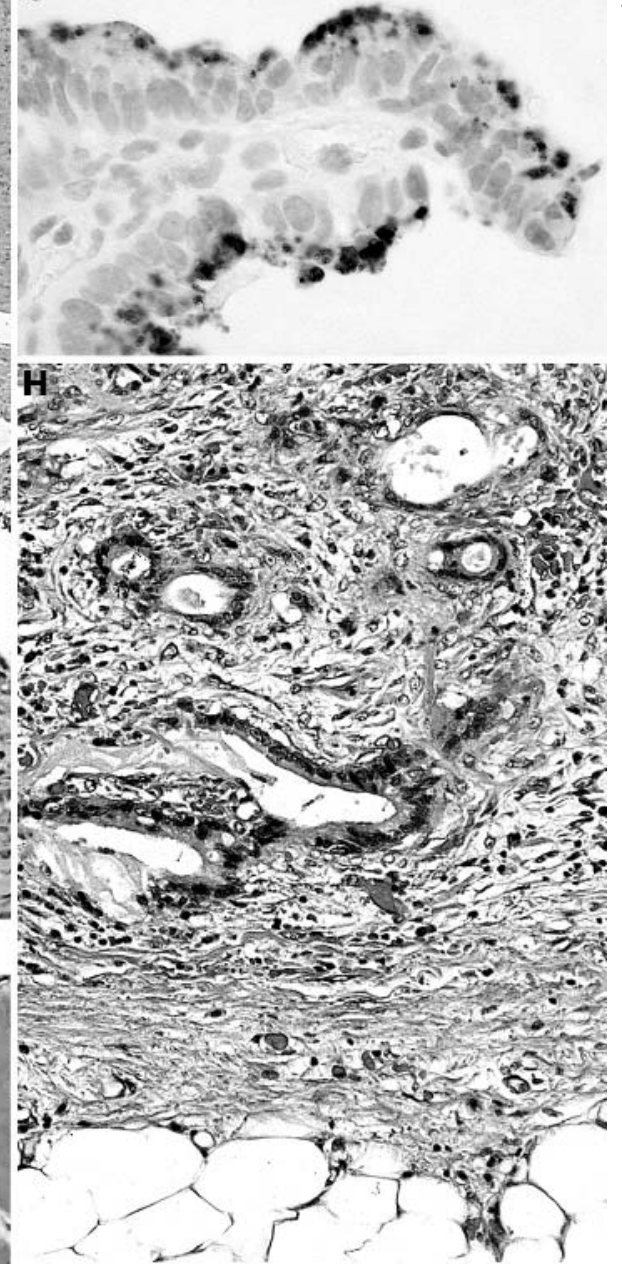

Figure 2 The cystic lesion. (A) The cyst was $7 \mathrm{~cm}$ in diameter, unilocular, and contained dark serosanguinous fluid. The lumen was granular and the wall was elastic hard. (B) Microscopically, the cyst wall had a well circumscribed smooth muscle layer, which

corresponded to the muscularis propria of the stomach (haematoxylin and eosin; original magnification, $\times 40$ ) Within the cyst, (C) simple cuboidal epithelium and (D) ciliated pseudostratified epithelium were seen (haematoxylin and eosin; original magnification, $\times 200$ ). (E) A well differentiated papillary tumour was seen (haematoxylin and eosin; original magnification, $\times 100$ ). (F) The fumour cell has hyperchromatic, atypical nuclei, corresponding to conventional adenocarcinoma (haematoxylin and eosin; original magnification, $\times 400$ ). (G) The cytoplasm of the tumour cells was immunopositive for human gastric mucin (NCL-HGM-45M1 antibody; avidin-biotin-peroxidase complex technique). (H) The carcinoma invaded the serosa of the cyst wall

(haematoxylin and eosin; original magnification, $\times 100$ ) epithelium derives from the alimentary tract. invaded the serosa of the cyst wall (fig $2 \mathrm{H}$ ).

In the stomach, the protruding tumour, measuring $4.5 \times 2.5 \mathrm{~cm}$, was seen at the anterior wall of the fundus 

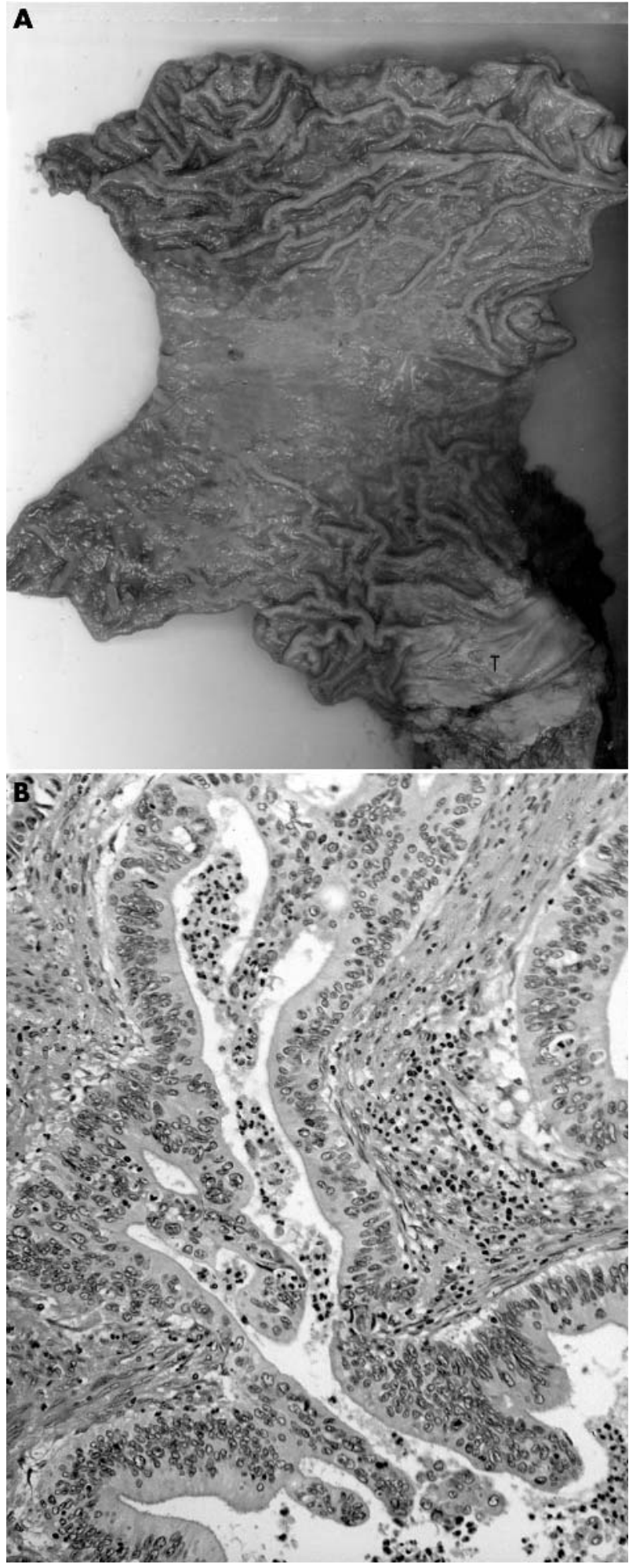

Figure 3 Adenocarcinoma in the stomach. (A) The protruding and ulcerative tumour (T), measuring $4.5 \times 2.5 \mathrm{~cm}$, was seen at the anterior wall of the fundus. (B) The tumour consisted of a well differentiated tubular or papillary adenocarcinoma (haematoxylin and eosin; original magnification, $\times 200$.)

(fig 3A). Microscopically, the tumour consisted mainly of well differentiated tubular or papillary structures. The carcinoma invaded the serosa to submucosa (fig 3B). Although we performed serial sections of the carcinoma, adenocarcinoma in situ was not detected in the stomach.
Table 1 Antibodies used for immunohistochemistry

\begin{tabular}{lll}
\hline Antigen (clone) & Source & Dilution \\
\hline Cytokeratin 7 & Novocastra, Newcastle & $1 / 50$ \\
(OV-TL 12/30) & upon Tyne, UK & \\
Cytokeratin 20 (Ks 20.8) & $\begin{array}{l}\text { Novocastra } \\
\text { p53 (DO-7) }\end{array}$ & $\begin{array}{l}\text { Dako, Kyoto, Japan } \\
\text { HGM-45M1 }\end{array}$ \\
(NCL-HGM-45M1) & Novocastra & $1 / 50$ \\
\hline
\end{tabular}

Immunohistochemistry revealed that the carcinoma cells in the stomach and duplication cyst had abnormal nuclear accumulation of $\mathrm{p} 53$ protein. These findings suggested that the carcinoma derived from a gastric duplication cyst that invaded the stomach wall. The carcinoma did not invade the spleen. Metastatic carcinoma was seen in one of the 25 regional lymph nodes dissected.

\section{DISCUSSION}

Gastrointestinal duplication is a rare congenital abnormality, which usually occurs in the ileum. ${ }^{1}$ Duplications of the stomach are relatively rare, comprising only $2-8 \%$ of all gastrointestinal duplications. ${ }^{9}$ Rowling summarised the essential criteria for the diagnosis of gastric duplication as described in the introduction section. ${ }^{3}$ The pathogenesis of alimentary tract duplications is controversial, but abnormal recanalisation after the solid epithelial stage of embryonic bowel development is thought by most to underlie these lesions. ${ }^{9}$ Differential diagnoses include congenital cyst of the pancreas, lymphoepithelial cyst of the pancreas, epithelial inclusion cyst of the spleen, post-traumatic pseudocyst of the spleen, and parasitic cyst of the spleen. Our present case fulfils the criteria for a gastric duplication cyst, and the possibility of another differential diagnosis is excluded. In our present case, adenocarcinoma found in the duplication cyst invaded the serosa of the cyst and the stomach wall. Neither adenocarcinoma in situ nor possible precancerous lesions, such as epithelial dysplasia, atrophic gastritis, or intestinal metaplasia, was detected in the stomach. These findings suggest that the carcinoma arose from a gastric duplication cyst that invaded the stomach.

"In our present case, adenocarcinoma found in the duplication cyst invaded the serosa of the cyst and the stomach wall"

Cancer arising from a gastric duplication cyst is extremely rare, with only five cases reported to date (table 2). ${ }^{4-7}$ Four of these cases were reported to be well differentiated adenocarcinoma, whereas another case was "infiltrating epithelial carcinoma". Two cases were located within the duplication cyst, whereas the other two cases invaded the stomach. The mucosa of duplication cysts tends to suffer from erosion and

\section{Take home messages}

- This report describes a rare case of adenocarcinoma arising from a gastric duplication cyst with invasion to the stomach wall

- Duplication cysts should be included in the differential diagnosis of cystic masses of the gastrointestinal tract, and the possibility of malignancy within these cysts should be considered 
Table 2 Clinicopathological characteristics of adenocarcinoma arising in a gastric duplication cyst

\begin{tabular}{|c|c|c|c|c|c|c|c|}
\hline $\begin{array}{l}\text { Patient } \\
\text { (ref) }\end{array}$ & Age/Sex & Symptoms & $\begin{array}{l}\text { Size of } \\
\text { cyst }(\mathrm{cm})\end{array}$ & $\begin{array}{l}\text { Macroscopic } \\
\text { appearance of } \\
\text { carcinoma }\end{array}$ & Histology & Invasion & Follow up \\
\hline $1(4)$ & $64 / F$ & $\begin{array}{l}\text { Weakness, } \\
\text { weight loss }\end{array}$ & 6 & $1.5 \mathrm{~cm}$, polypoid & $\begin{array}{l}\text { Well differentiated } \\
\text { glandular carcinoma }\end{array}$ & $\begin{array}{l}\text { Muscular wall } \\
\text { of the stomach }\end{array}$ & NED at 12 months \\
\hline $2(5)$ & $50 / M$ & Vomiting, weight loss & 17 & Ulcerative tumour & Infiltrating epithelial carcinoma & Unknown & Unknown \\
\hline $3(6)$ & $72 / F$ & $\begin{array}{l}\text { Abdominal } \\
\text { pain, weight loss }\end{array}$ & 4 & Granular & $\begin{array}{l}\text { Mucinous } \\
\text { papillary adenocarcinoma }\end{array}$ & $\begin{array}{l}\text { Submucosa } \\
\text { of the stomach }\end{array}$ & NED at 72 months \\
\hline $4(7)$ & $56 / M$ & $\begin{array}{l}\text { Vomiting, } \\
\text { weight loss }\end{array}$ & 10 & $\begin{array}{l}0.7 \mathrm{~cm} \text {, superficial } \\
\text { slightly depressed }\end{array}$ & $\begin{array}{l}\text { Well } \\
\text { differentiated adenocarcinoma }\end{array}$ & Mucosa of the cyst & NED at 28 months \\
\hline $5(8)$ & $71 / \mathrm{F}$ & $\begin{array}{l}\text { Abdominal } \\
\text { pain, appetite loss }\end{array}$ & 8 & $\begin{array}{l}2.0 \mathrm{~cm} \text {, superficial } \\
\text { slightly raised }\end{array}$ & Papillary adenocarcinoma & Wall of the cyst & NED at 1 month \\
\hline $\begin{array}{l}6 \text { (present } \\
\text { case) }\end{array}$ & $40 / M$ & Fever, back pain & 7 & Multifocal, granular & $\begin{array}{l}\text { Well differentiated tubular } \\
\text { or papillary adenocarcinoma }\end{array}$ & $\begin{array}{l}\text { Whole wall } \\
\text { of the stomach }\end{array}$ & $\begin{array}{l}\text { Liver metastasis } \\
\text { at } 7 \text { months }\end{array}$ \\
\hline
\end{tabular}

to show regenerative change. Ectopic tissues, such as ectopic pancreas, are often found in the mucosa of duplication cysts. These would cause adenocarcinoma in duplication cysts. ${ }^{10}$ In the present case, erosion and regenerative epithelia were present in the mucosa of the cyst, although there was no ectopic tissue. Some of the patients, including our present case, are relatively young (table 2), suggesting that mucosa of the duplication cyst has a high risk of carcinogenesis.

In summary, this unusual developmental abnormality should be included in the differential diagnosis of partially obstructing cystic masses of the gastrointestinal tract, and the possibility of malignancy within it should be considered.

\section{ACKNOWLEDGEMENTS}

We are grateful to $\mathrm{Mr}$ M Takatani, Department of Molecular Pathology, Hiroshima University Graduate School of Biomedical Sciences, and the staff members at the Pathology Division, Hiroshima City Medical Association Clinical Laboratory for skilful technical assistance.

\footnotetext{
Authors' affiliations

K Kuraoka, H Nakayama, W Yasui, Department of Molecular Pathology, Hiroshima University Graduate School of Biomedical Sciences, 1-2-3 Kasumi, Minami-ku, Hiroshima, 734-8551, Japan T Kagawa, T Ichikawa, Department of Surgery, Hiroshima Municipal Funairi Hospital, 14-11 Funairi-saiwaityo, Naka-ku, Hiroshima, 7300844, Japan
}

Correspondence to: Dr W Yasui, Department of Molecular Pathology, Hiroshima University Graduate School of Biomedical Sciences, 1-2-3 Kasumi, Minami-ku, Hiroshima, 734-8551, Japan; wyasui@hiroshima-u. ac.jp

Accepted for publication 19 November 2003

\section{REFERENCES}

1 Bower RJ, Silber WK, Kiesewetter WB. Alimentary tract duplication in children. Ann Surg 1978;188:669-74.

2 Wieczorek RL, Seidman I, Ranson JH, et al. Congenital duplication of the stomach: case report and review of the English literature. Am J Gastroenterol 1984;79:597-602.

3 Rowling JT. Some observations on gastric cysts. Br J Surg 1959;46:441-5.

4 Mayo HW, McKee EE, Anderson RM. Carcinoma arising in reduplication of the stomach (gastrogenous cyst): a case report. Ann Surg 1955;141:550-5.

5 Treiger M, Rubens J, Chindler J, et al. Stomach duplication. Report of a 2nd case in literature complicated by a peptic ulcer and malignant neoplasms (in Portuguese). Hospital Rio J 1969;75:1-10.

6 Coit DG, Mies C. Adenocarcinoma arising within a gastric duplication cyst. J Surg Oncol 1992;50:274-7.

7 Ishikawa M, Samejima N, Matsushita M, et al. A case of early cancer of the duplicated stomach accompanied with gastric cancer (in Japanese). Jpn J Gastroenterol Surg 1988;21:2148-51.

8 Mamiya N, Karasawa Y, Kojima N, et al. A case of gastric duplication cyst containing papillary adenocarcinoma (in Japanese). Jpn J Gastroenterol 1996;93:34-8.

9 Gross RE, Holcomb JW, Farber S. Duplication of the alimentary tract. Pediatrics 1952;9:449-67.

10 Iwanaga T, Koyama H, Takahashi $Y$, et al. Diffuse submucosal cysts and carcinoma of the stomach. Cancer 1975;36:606-14. 